\title{
Increased PD-1 Level in Severe Cervical Injury Is Associated With the Rare Programmed Cell Death 1 (PDCD1) rs36084323 A Allele in a Dominant Model
}

\section{OPEN ACCESS}

Edited by:

John Hiscott,

Istituto Pasteur Italia Cenci Bolognetti

Foundation, Italy

Reviewed by:

Kalichamy Alagarasu,

National Institute of Virology (ICMR),

India

Teneema Kuriakose,

St. Jude Children's Research Hospital, United States

*Correspondence:

Norma Lucena-Silva norma.lucena@hotmail.com

Specialty section: This article was submitted to Virus and Host,

a section of the journal

Frontiers in Cellular and

Infection Microbiology

Received: 28 July 2020 Accepted: 21 April 2021

Published: 01 July 2021

Citation:

Silva MC, Medeiros FS,

Silva NCH, Paiva LA, Gomes FOdS,

Costa e Silva M, Gomes TT,

Peixoto CA, Rygaard MCV, Menezes MLB, Welkovic S, Donadi EA and Lucena-Silva N (2021) Increased

PD-1 Level in Severe Cervical

Injury Is Associated With the

Rare Programmed Cell Death

1 (PDCD1) rs36084323 A

Allele in a Dominant Model.

Front. Cell. Infect. Microbiol. 11:587932.

do: 10.3389/fcimb.2021.587932
Mauro César da Silva ${ }^{1}$, Fernanda Silva Medeiros ${ }^{1}$, Neila Caroline Henrique da Silva ${ }^{1}$, Larissa Albuquerque Paiva ${ }^{2}$, Fabiana Oliveira dos Santos Gomes ${ }^{1}$, Matheus Costa e Silva ${ }^{3}$, Thailany Thays Gomes ${ }^{1}$, Christina Alves Peixoto ${ }^{1}$, Maria Carolina Valença Rygaard ${ }^{4}$, Maria Luiza Bezerra Menezes ${ }^{5}$, Stefan Welkovic ${ }^{6}$, Eduardo Antônio Donadi ${ }^{3}$ and Norma Lucena-Silva ${ }^{1,4 *}$

${ }^{1}$ Laboratory of Immunogenetics, Department of Immunology, Aggeu Magalhães Institute, Oswaldo Cruz Foundation, Recife, Brazil, ${ }^{2}$ Getúlio Vargas Hospital, Pernambuco Health Department, Recife, Brazil, ${ }^{3}$ Clinical Immunology Division, Department of Medicine, School of Medicine of Ribeirão Preto, University of São Paulo (USP), Ribeirão Preto, Brazil, ${ }^{4}$ Laboratory of Molecular Biology, IMIP Hospital, Pediatric Oncology Service, Recife, Brazil, ${ }^{5}$ Department of Maternal and Child, Faculty of Medical Sciences, University of Pernambuco, Recife, Brazil, 6 Integrated Health Center Amaury de Medeiros (CISAM),

University of Pernambuco, Recife, Brazil

The high-risk oncogenic human papillomavirus (HPV) has developed mechanisms for evasion of the immune system, favoring the persistence of the infection. The chronic inflammation further contributes to the progression of tissue injury to cervical cancer. The programmed cell death protein (PD-1) after contacting with its ligands (PD-L1 and PD-L2) exerts an inhibitory effect on the cellular immune response, maintaining the balance between activation, tolerance, and immune cell-dependent lesion. We evaluated 295 patients exhibiting or not HPV infection, stratified according to the location (injured and adjacent non-injured areas) and severity of the lesion (benign, pre-malignant lesions). Additionally, we investigated the role of the promoter region PDCD1 -606G $>A$ polymorphism (rs36084323) on the studied variables. PD-1 and PDCD1 expression were evaluated by immunohistochemistry and $\mathrm{QPCR}$, respectively, and the PDCD1 polymorphism was evaluated by nucleotide sequencing. Irrespective of the severity of the lesion, PD-1 levels were increased compared to adjacent uninjured areas. Additionally, in cervical intraepithelial neoplasia $(\mathrm{CIN}) \mathrm{I}$, the presence of HPV was associated with increased $(P=0.0649)$, whereas in CIN III was associated with decreased $(P=0.0148)$ PD-1 levels, compared to the uninjured area in absence of HPV infection. The PDCD1 -606A allele was rare in our population (8.7\%) and was not associated with the risk for development of HPV infection, cytological and histological features, and aneuploidy. In contrast, irrespective of the severity of the lesion, patients exhibiting the mutant PDCD1 -606A allele at single or double doses exhibited increased protein and gene expression when compared to the PDCD1 -606GG wild type genotype. Besides, the presence of 
HPV was associated with the decrease in PDCD1 expression and PD-1 levels in carriers of the -606 A allele presenting severe lesions, suggesting that other mediators induced during the HPV infection progression may play an additional role. This study showed that increased PD-1 levels are influenced by the $-606 \mathrm{G}>\mathrm{A}$ nucleotide variation, particularly in low-grade lesions, in which the A allele favors increased $P D C D 1$ expression, contributing to HPV immune system evasion, and in the high-grade lesion, by decreasing tissue PD1 levels.

Keywords: PD-1, CIN, HPV, polymorphism, inflammation, cancer

\section{INTRODUCTION}

Human papillomavirus (HPV) is the most common sexually transmitted biological agent, responsible for causing several types of cancer, particularly in the anogenital region, accounting for about $85 \%$ of the cervical tumors (World Health Organization, 2017; De Oliveira et al., 2019). The high-risk oncogenic HPVs have developed immune system evasion mechanisms, favoring viral persistence and chronic inflammation, which play an important role in the progression from cervical injury to cancer (Aggarwal et al., 2006; Grivennikov et al., 2010; Senba and Mori, 2012; Marinelli et al., 2019).

The programmed cell death protein (PD-1), together with its ligands PD-L1 or PD-L2, exerts an inhibitory effect on the cellular immune response, maintaining the balance between activation and tolerance of the immune cell function. The PD1/PD-L1 signaling pathway has been used by microorganisms and tumor cells to decrease host immune system activity, permitting chronic infection, cell transformation into the tumor, and tumor cell survival (Ishida et al., 1992; Keir et al., 2008). PD-1 protein is mainly expressed on the membrane of Tand B- lymphocytes, NK cells, dendritic cells, activated monocytes, and immature Langerhans cells (Boussiotis, 2016).

Belonging to the immunoglobulin superfamily, PD-1 is a type I transmembrane monomeric protein, which has a cytoplasmic tyrosine-based inhibitory motif (ITIM) and a tyrosine-based switch motif (ITSM) that transmit inhibitory signals to the

\footnotetext{
Abbreviations: Akt, Protein kinase B; ASC - H, Atypical squamous cells-cannot exclude high-grade squamous intraepithelial lesion; ASC-US, Atypical squamous cells of undetermined significance; CI, Confidence interval; CIN, Cervical intraepithelial neoplasia (I-III); CISAM, Integrated Health Center Amaury de Medeiros; DNA, Deoxyribonucleic acid; DMSO, Dimethyl sulfoxide; GAPDH, Glyceraldehyde phosphate dehydrogenase; HE, Hematoxylin-eosin; HBV, Hepatitis B virus; HIV, Human immunodeficiency virus; HLA-G, Human leukocyte antigen G; HPV, Human papillomavirus; HSIL, High-grade squamous intraepithelial lesion; IMIP, Professor Fernando Figueira Institute of Integral Medicine; IHC, Immunohistochemistry; ITIM, Immunoreceptor tyrosine-based inhibitory motif; ITSM, Immunoreceptor tyrosine-based switch motif; LGSIL, Low-grade squamous intraepithelial lesion; NSCLC, Non-small cell lung cancer; OEGE, Online Encyclopedia for Genetic Epidemiology; OR, Odds ratio; $P, P$ value; PBMC, Peripheral blood mononucleated cells; PCR, Polymerase chain reaction; PI3K, Phosphatidylinositol 3-kinase; PD-1/PDCD1, Programmed cell death 1; PD-L1/PD-L2, Programmed cell death ligand 1 or 2; SNP, Single nucleotide polymorphisms; SSPE, Subacute sclerosing panencephalitis; TAE, Tris-acetate-EDTA buffer; TCR, T-cell receptor; UTR, Untranslated regions.
}

immune system cells. Once the peptide-MHC complex on the surface of the antigen-presenting cell (APC) binds to the T-cell receptor (TCR), the PD-L1 expressed on APC binds to the PD-1 receptor on T-cells and induces the phosphorylation of ITIM and ITSM motifs. The recruitment of the SHP-1 and SHP-2 phosphatases causes dephosphorylation of other signaling molecules of the cascade, inhibiting phosphatidylinositol 3kinase $(\mathrm{PI} 3 \mathrm{~K})$ and protein kinase $\mathrm{B}$ (Akt). These events culminate in immune response inhibition, reflected by i) decreased production of cytokines, such as IFN- $\gamma$, IL-2, and TNF- $\alpha$, ii) inhibition of proliferation and survival of T cells, and iii) re-establishment of the immunological homeostasis, decreasing the expression of co-stimulatory molecules at the immunological synapsis (Muenst et al., 2016; Salmaninejad et al., 2018). Nevertheless, the PD-1/PD-L1 signaling pathway may be used by tumor cells to attenuate or escape anti-tumor immunity, facilitating tumor progression. In human malignancies, high Tcell PD-1 expression has been reported in Hodgkin's lymphoma, chronic lymphocytic leukemia, and breast, bladder, and ovarian cancers, suggesting a state of functional exhaustion of $\mathrm{T}$ cells (Muenst et al., 2016; Hollander et al., 2018; Kawahara et al., 2018; Lewinsky et al., 2018; Wieser et al., 2018; Jiang et al., 2019).

The PDCD1 gene is located at chromosome 2 (2q37.3), presents 5 exons, and encodes a 288 amino acid PD-1 protein. Alternative splicing can generate different isoforms that are expressed at similar levels after $\mathrm{T}$ cell activation (Shinohara et al., 1994; Keir et al., 2008); however, genetic variants at PDCD1 coding and regulatory 5' and 3' untranslated regions (UTR) may influence protein levels and the natural history of cancer development (Tao et al., 2017; Wang et al., 2018). Several PDCD1 polymorphic sites have been described, including i) 298 single nucleotide polymorphisms (SNPs) at the coding region, of which 213 missense, 112 synonymous, 7 nonsense, and 4 frameshift mutations; ii) 512 SNPs at the extended 5'UTR, iii) 490 SNPs at the extended 3'UTR, and iv) 1,791 intronic sequence mutations. Among these SNPs, 36 at the coding region, 57 at 5'UTR, 56 at 3'UTR and 283 intronic ones have clinical importance (https://www.ncbi.nlm.nih.gov/SNP/). Among all these polymorphic sites, the PDCD1 promoter region $-606 \mathrm{G}>\mathrm{A}$ polymorphism (rs36084323) has been associated with the oncogenic p53 protein in breast cancer (Hua et al., 2011), in measles-induced autoimmune neurological manifestations (Ishizaki et al., 2010), and the susceptibility to hepatitis B infection (Hou et al., 2017). 
To study the role of PD-1 on the progression of cervical lesions, we evaluated PD-1 tissue and PDCD1 gene expression in women infected or not by HPV. To understand the contribution of genetic factors on $\mathrm{PD}-1$ and $P D C D 1$ expression, we evaluated the $P D C D 1$ promoter region $-606 \mathrm{G}>\mathrm{A}$ polymorphism (rs36084323) in these patients.

\section{MATERIALS AND METHODS}

\section{Study Population and Ethical Consideration}

The study population encompassed 295 women, aged 18-71 years (median=37 years). Among the $107 \mathrm{HPV}$-infected women, 90 were infected by high-risk, 11 by low-risk HPV, and in 6 samples the HPV viral genotype was not identified. Patients attending the Integrated Health Center Amaury de Medeiros (CISAM) and in the Professor Fernando Figueira Institute of Integral Medicine (IMIP), in Pernambuco, Brazil, between April 2016 to October 2018, were invited to participate in this study during the routine gynecological consultations for evaluation of the Papanicolaou smears, which are performed annually in asymptomatic and symptomatic women. This study was approved by the Ethics Committee of the Aggeu Magalhães Institute (CAAE: 51111115.9.0000.5190), and all participants signed an informed consent form after receiving a detailed explanation about the research. HIV-positive patients were not included in this study.
Clinical and laboratory data were obtained from medical records and interviews, using a standard questionnaire (Table 1). Venous blood and cervical exfoliative cells and biopsies were obtained during routine colposcopy analysis and evaluated by experienced gynecologists.

For the $P D C D 1$ gene expression analysis, the reference group was women presenting no atypia in the cytopathological Papanicolaou smear, who were not eligible to be subjected to biopsy due to ethical restriction. Abnormal cytology was classified using the Bethesda system. Cervical abnormalities were stratified as the low-grade squamous intraepithelial lesion (LGSIL) and high-grade squamous intraepithelial lesion (HGSIL). Women presenting abnormal cytology were subjected to cervical biopsies for histological stratification into the benign lesions, low-grade cervical intraepithelial neoplasia (CIN) I, and highgrade CIN II and CIN III. For the immunohistochemistry evaluation of PD-1 protein levels, the reference controls were specimens from the uninjured area adjacent to the lesion.

\section{Histopathology}

Biopsies of the cervical lesion and the adjacent area were fixed in formalin (10\%) and embedded in paraffin. Four $\mu \mathrm{m}$ tissue sections were cut using a manual microtome (American Optical, Rotary, Leica, Buffalo Grove, IL), placed on silanized glass slides (Agilent-Dako, Santa Clara, CA), stained with hematoxylin-eosin (HE) and mounted with the medium

TABLE 1 | Demographic, clinical, and laboratory features of women exhibiting cervical lesion associated with the HPV-infections [low-grade squamous intraepithelial lesion (LGSIL), the high-grade squamous intraepithelial lesion (HGSIL) and cervical intraepithelial neoplasia (CIN)] or non-associated with the HPV infection [atypical squamous cells of undifferentiated (ASC-US), atypical squamous cells not excluding high-grade squamous intraepithelial lesion (ASC-H)].

\begin{tabular}{|c|c|c|c|c|c|c|c|}
\hline \multirow[t]{2}{*}{ Patients characteristics } & \multicolumn{2}{|c|}{ TOTAL } & \multicolumn{2}{|c|}{ HPV + } & \multicolumn{2}{|c|}{ HPV - } & \\
\hline & $N=295$ & $\%$ & $N=107$ & $36.3 \%$ & $N=188$ & $63.7 \%$ & \\
\hline \multicolumn{8}{|l|}{ Age - years } \\
\hline Median (minimum - maximum) & $37.8(18-70)$ & & $36(18-66)$ & & $38(19-72)$ & & $P=0.3066$ \\
\hline Use of oral contraceptives & 293 & & 107 & & 188 & & \\
\hline Yes & 68 & 23.2 & 19 & 17.9 & 49 & 26.2 & $P=0.1152$ \\
\hline No & 225 & 76.8 & 87 & 82.1 & 138 & 73.8 & \\
\hline Data missing & 2 & & 1 & & 1 & & \\
\hline Cytological alterations & 255 & & 107 & & 188 & & \\
\hline No atypias & 104 & 40.8 & 24 & 25.5 & 80 & 49.6 & $P<0.0001$ \\
\hline ASC-US and ASC-H & 26 & 10.2 & 6 & 6.4 & 20 & 12.4 & \\
\hline LGSIL & 51 & 20.0 & 22 & 23.4 & 29 & 18.0 & \\
\hline HGSIL & 74 & 29.0 & 42 & 44.7 & 32 & 19.9 & \\
\hline Data missing & 40 & & 13 & & 27 & & \\
\hline Histological alterations & 267 & & 107 & & 188 & & \\
\hline Uninjured (not submitted to biopsy) & 74 & 27.7 & 11 & 11.7 & 63 & 36.4 & $P<0.0001$ \\
\hline Benign injury & 41 & 15.4 & 9 & 9.6 & 32 & 18.5 & \\
\hline CIN I & 23 & 8.6 & 8 & 8.5 & 15 & 8.7 & \\
\hline $\mathrm{CIN} \|$ & 67 & 25.1 & 33 & 35.1 & 34 & 19.6 & \\
\hline CIN III & 62 & 23.2 & 33 & 35.1 & 29 & 16.8 & \\
\hline Data missing & 24 & & 13 & & 15 & & \\
\hline Cellular ploidy & 122 & & 107 & & 188 & & \\
\hline Aneuploidy & 27 & 22.1 & 10 & 23.8 & 63 & 78.8 & $P<0.0001$ \\
\hline Diploidy & 95 & 77.9 & 32 & 76.2 & 17 & 21.2 & \\
\hline Data missing & 173 & & 65 & & 108 & & \\
\hline
\end{tabular}

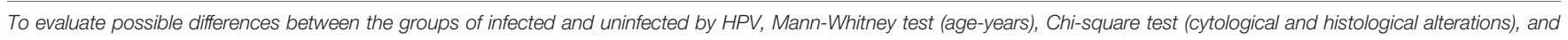

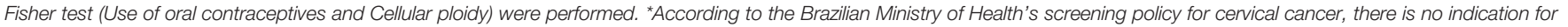
colposcopy for these patients, due to the absence of changes in the cytological examination. 
Entellan ${ }^{\circledR}$ (MERCK, Burlington, MA). The sections were visualized with 400x magnification in an inverted microscope (Zeiss, Göttingen, Germany) equipped with a camera and with a 4.7.4 Image Analysis Program (AxionCam MRm Zeiss). HEstained slides were blindly evaluated by a cervical pathologist.

\section{HPV Detection and Typing}

Genomic DNA was extracted from $500 \mu \mathrm{L}$ of a cervical cell suspension, using the Illustra Blood kit (Healthcare ${ }^{\circledR}$, Little Chalfont, Buckinghamshire, UK), according to the manufacturer's instructions, and quantified using the NanoDrop 2000 spectrophotometer (ThermoScientific, Waltham, MA). The quality of the extracted DNA was also assessed by PCR-amplification using the human constitutive glyceraldehyde phosphate dehydrogenase (GAPDH) gene (Martins et al., 2014). HPV infection in cervical samples was diagnosed by amplifying a fragment of the viral $L 1$ gene with the degenerate MY09 and MY11 primers (Manos et al., 1989), using the L1-fragment encoded plasmid as the positive control. A reaction without adding any sample was used as a negative control. The presence of a band of approximately 450 base pairs (bp) in the $2 \%$ agarose gel confirmed the presence of the viral infection. Each amplification product was directly sequenced with the MY11 primer in the Genetic AnalyzerABI 3500 (Applied Biosystems, Foster City, CA) sequencer, using the BigDye terminator v3.1 cycle sequencing kit (Applied Biosystems). The chromatograms were visualized in the Mega 6.0 program (Tamura et al., 2011) to assess the quality of the sequence. Samples with defined peaks and low background in the chromatogram were submitted to Papillomavirus Episteme (https://pave.niaid.nih.gov/) to HPV genotyping.

\section{Determination of Cellular Ploidy}

Cervical cells of the uterine cervix $(150 \mu \mathrm{L})$ were ruptured using $2 \mathrm{~mL}$ of Pharm Lyse lysis buffer (Becton Dickinson, Franklin Lakes, NJ), vigorously homogenized, and incubated in the dark for 10 minutes, and centrifuged for 120 seconds at 1,000 $\mathrm{xg}$. The supernatant was discarded and the pellet resuspended in $2 \mathrm{~mL}$ of FACs flow buffer, gently homogenized, and recentrifuged for 120 seconds at 1,000 $\mathrm{x}$ g. After discarding the supernatant, the pellet was resuspended in $500 \mu \mathrm{L}$ of propidium iodide plus $10 \mu \mathrm{L}$ of RNase $(100 \mu \mathrm{g} / \mathrm{mL})$, and incubated at room temperature for 30 minutes at $4^{\circ} \mathrm{C}$ and then for 10 minutes at $8^{\circ} \mathrm{C}$. DNA fluorescence was measured by laser excitation at $488 \mathrm{~nm}$ and emission above $600 \mathrm{~nm}$. The DNA index was estimated by comparing the proportion of DNA from the cervical cells analyzed with the diploid blood cells, using the software ModFitLT V3.0 (Verity Software House Inc., Topsham, ME). Aneuploidy was defined by a deviation in the DNA histogram in more than $10 \%$ of the cell population analyzed in the area corresponding to G0- G1 of the cell cycle in the sample (Martins et al., 2014).

\section{Cervical Cell PD-1 Levels}

Immunohistochemistry (IHC) analysis for cervical biopsies was manually performed using the DAKO EnVision ${ }^{\mathrm{TM}}$ FLEX kit
(Agilent-DAKO, Santa Clara, CA). For antigenic recovery, tissue was pretreated with citrate buffer, $\mathrm{pH} 6.1$ (Agilent-DAKO), and heated for 30 minutes. After blocking with endogenous peroxidase, the tissue sample was incubated with the primary monoclonal anti-PD-1 mouse antibody (ABCAM, Cambridge, UK) diluted (1:100) with DAKO antibody diluent for 1 h. After washing, the sections were incubated with secondary antibody for 20 minutes and then visualized with the DAB reagent $\left(3,3^{\prime}\right.$ diaminobenzidine tetrahydrochloride, DAKO). After labeling, tissue sections were counterstained with Harris' hematoxylin and assembled with Entellan ${ }^{\circledR}$ (MERCK).

The IHC slides of the cervical lesion and the adjacent uninjured area were independently analyzed by two specialist pathologists. Cell areas showing brown staining were considered to be positive for the expression of PD-1 and quantified in three fields showing the highest labeling per slide, using the Gimp 2.10.18 software (GNU Image Manipulation Program, UNIX platforms, www.gimp.org). To minimize possible reading errors, we measured pixels in areas with an intense and less intense stained area in the same picture; and combined both readings to generate the final PD-1 expression value.

\section{Cervical Cell PDCD1 Gene Expression}

Total RNA was extracted from a $1000 \mu \mathrm{L}$ of cervical cell suspension, using Trizol ${ }^{\circledR}$ reagent (Invitrogen), and submitted to cDNA synthesis using the MLLV reverse transcriptase (Invitrogen), accordingly to the manufacturer's instructions. For PDCD1 expression, the qPCR was prepared with $1 \mu \mathrm{L} \mathrm{cDNA}$ and 10 pmoles of each PD1F: 5' GAT GGT TCT TAG ACT CCC CAG ACA G 3', and PD1R: 5' GGC TCA TGC GGT ACC AGT TTA GCA C 3' primers, in Power SYBR ${ }^{\mathrm{TM}}$ Green PCR Master Mix (Applied Biosystems, Foster City, CA). For the expression of the GAPDH constitutive gene, we used also $1 \mu \mathrm{L}$ cDNA and 10 pmoles of GAPDH2F: 5' AGA AGG CTG GGG CTC ATT TG 3' and GAPDH2R: 5' GTG GTC ATG AGT CCT TCC AC 3' primers in Power SYBR ${ }^{\mathrm{TM}}$ Green PCR Master Mix. All primers were designed nearby the exon-intron junction to amplify a fragment that covers two exons, assuring amplification of the cDNA target. The qPCR was performed in a final volume of $20 \mu \mathrm{L}$ containing $10 \mu \mathrm{L}$ of $2 \times$ Power SYBR ${ }^{\circledR}$ Green PCR Master Mix, $1 \mu \mathrm{l}$ forward and $1 \mu \mathrm{l}$ reverse PCR primers (500nM), $1 \mu \mathrm{L}$ cDNA and 7 $\mu \mathrm{L}$ nuclease-free water. The reaction mixtures were processed with an initial holding period at $95^{\circ} \mathrm{C}$ for $10 \mathrm{~min}$, followed by a twostep PCR program for 40 cycles that consisted of $95^{\circ} \mathrm{C}$ for $15 \mathrm{sec}$ and $60^{\circ} \mathrm{C}$ for $1 \mathrm{~min}$. The PDCD1 and GAPDH calibration curves showed similar amplification efficiency, and samples were evaluated in duplicate in Quant Studio 5 (Applied Biosystem). Only samples showing a melting curve with single and specific peaks, and only duplicates showing standard deviation less than 0.5 were considered for analyses. A unique threshold was settled for each gene amplification in all plates, and the sample CTs were annotated. PDCD1 relative expression was determined by $\triangle \mathrm{CT}$ comparative quantification, in which PDCD1 expression was normalized by the endogenous gene expression $\left(\triangle \mathrm{CT}=\mathrm{CT}_{\mathrm{PDCD} 1}\right.$ - $\mathrm{CT}_{\mathrm{GAPDH}}$ ) for each sample, and the final results were expressed in fold-change, using the equation (Fold-change $=2^{-\Delta C T}$ ). 


\section{PDCD1 Promoter Region Polymorphism}

DNA from peripheral blood mononuclear cells, extracted using DNAzol $^{\circledR}$ Reagent (Invitrogen, Carlsbad, CA) was used for the detection of the $-606 \mathrm{G}>\mathrm{A}$ (rs36084323) SNP. Briefly, DNA was amplified using the $P D-1$ PROMO F (5 'GAA AGA TCT GGA ACT GTG GC 3') and PD-1 PROMO R (5 'TGA GAG TGA AAG GTC CCT CC 3') primers. The amplification reaction was performed in a final volume of $20 \mu \mathrm{L}$ containing $1 \mathrm{x}$ of polymerase buffer (Applied Biosystems), $0.5 \mathrm{mM} \mathrm{MgCl}_{2}, 2 \%$ DMSO, $200 \mu \mathrm{M}$ dNTP's, $1.0 \mu \mathrm{M}$ of each primer, 1.0 unit of Ampli-Taq Gold (Applied Biosystems) and 80-200 ng of genomic DNA for the amplification of a $962 \mathrm{bp}-\mathrm{PD} 1$ fragment. The cycling conditions included an initial stage at $94^{\circ} \mathrm{C}$ for $10 \mathrm{~min}$; 40 cycles of denaturation at $94^{\circ} \mathrm{C}$ for $1 \mathrm{~min}$, annealing at $62{ }^{\circ} \mathrm{C}$ for $1 \mathrm{~min}$ and extension at $72{ }^{\circ} \mathrm{C}$ for $1.2 \mathrm{~min}$, and final extension for $7 \mathrm{~min}$ at $72^{\circ} \mathrm{C}$. The PCR product was visualized using a $1.5 \%$ agarose gel and, subsequently, sequenced by the SANGER method, following the BigDye protocol on ABI 3500 sequencer (Applied Biosystems). Polymorphic sites were determined using the Seqman ${ }^{\circledR}$ program (Roche 454, Life ScienceTM, Branford, CT) and individually annotated in an Excel 2016 spreadsheet.

\section{Bioinformatics Analysis}

To propose a list of possible microRNAs (miRNA) associated with the PDCD1 rs36084323 SNP, we took advantage of two separated approaches using: i) the mirDIP Version 4.1.11.1 (Tokar et al., 2018), which integrates 30 different databases of miRNA target prediction, together with a unidirectional search query with PDCD1 (PD-1 alias), to search for all predicted miRNAs without filtering any specific 'Score class'; ii) the sequence of 100 base pairs that surrounds the SNP, as retrieved from Genome Browser Gateway (http://genome.ucsc. edu/), and blasted using miRBase Release 22.1 (Kozomara et al., 2019). Then, we selected the miRNAs that annealed with the SNP site taking into account the two possible alleles.

\section{Statistical Analysis}

Association analyses of allele and genotype frequencies with clinical variables were performed using the two-tailed Fisher's exact and chi-square tests, considering a significance level of $P<0.05$. The Hardy-Weinberg Equilibrium was assessed by the Online Encyclopedia for Genetic Epidemiology (OEGE). The D'Agostino-Pearson test was used to assess the homogeneity of the PD-1 expression in pixels and fold-change. The central tendency was expressed as a median and the Kruskal-Wallis and Mann-Whitney tests were used to compare numeric variables. The graphics were prepared using GraphPad Prism Software version 5.0 for windows (www.graphpad.com, La Jolla, CA).

\section{RESULTS}

\section{PD-1 Detection in Cervical Samples}

PD-1 expression was evaluated in samples exhibiting HPV infection and in samples without HPV infection. Irrespective of lesion severity, we observed three patterns of PD-1 staining in cervical samples: i) exclusive labeling of the stratified squamous epithelium, ii) exclusive labeling of stromal cells, and iii) labeling of epithelium and stroma. Considering the uninjured adjacent areas, the expression of PD- 1 in epithelium and stroma $(n=50$, median $=4,313$ pixels) was higher when compared to sections that labeled only the epithelium ( $\mathrm{n}=48$, median $=2,810$ pixels, $P=0.0302$ ). Considering the injured areas (cervical lesions), the expression of PD-1 in epithelium and stroma $(n=32$, median $=$ 21,184 pixels) was also significantly higher when compared to specimens that exclusively labeled the epithelium area $(n=20$, median $=6,339$ pixels, $P<0.0001$ ) (Figure 1A).

The evaluation of $\mathrm{PD}-1$ protein level according to the severity of the lesion revealed the following results: i) PD-1 expression in benign lesions, and cervical intraepithelial neoplasia (CIN I, CIN II, and CIN III) was significantly higher when compared to uninjured adjacent tissue $(P<0.0001$, for each comparison, Figure 1B); ii) the PD-1 expression in benign lesions did not differ from CIN II $(P=0.7431)$ and CIN III $(P=0.5854)$ and, similarly, CIN II did not differ from CIN III $(P=0.5122)$; and iii) the PD-1 levels in low-grade lesions $(\mathrm{CIN} I)(\mathrm{n}=12$, median $=$ 44,215 pixels) were higher than in those presenting high-grade (CIN II and CIN III) lesions $(\mathrm{n}=54$, median $=18,942$ pixels, $P=$ 0.0046); however, the pattern of expression was different. PD-1 labeling in low-grade lesions was higher in infiltrating immune cells of the stroma compared to the epithelium, whereas in highgrade lesions PD-1 expression was observed primarily in the epithelium (Figure 2). Additionally, irrespective of the severity of the lesion, PD-1 levels were increased compared to adjacent uninjured areas. Also, in CIN I the presence of HPV was associated with increased PD-1 protein levels $(P=0.0649)$, whereas in CIN III was associated with decreased levels $(P=$ 0.0148 ) compared to correspondent tissue lesion in absence of HPV infection (Figures 1C, D).

\section{Polymorphism of the PDCD1 Promoter Region}

Irrespective of the severity of the cervical lesion, the frequency of the wild $-606 \mathrm{G}$ allele was $91.3 \%$, and the distribution of the GG (83.7\%), GA (15.2\%), and AA (1.1\%) genotypes adhered to the Hardy-Weinberg equilibrium $\left(\chi^{2}=0.48\right)$. Taking into account the low frequency of the AA genotype, we lumped together the $\mathrm{AA}$ and GA genotypes to allow statistical analysis. Women carrying the $-606 \mathrm{~A}$ allele were not at increased risk for i) development of HPV infection, ii) exhibiting cytological and histological HPV and non-HPV changes, and ii) presenting aneuploidy (Table 2).

Considering the differential exposure of HPV according to age and the risk for developing cervical lesions, we evaluated the influence of the patient age on the studied variables. Age did not influence the PDCD1 genotype frequency among patients presenting or not $\operatorname{HPV}(P=0.3066)$, and among patients exhibiting benign injury $(P=0.1692)$, CIN I $(P=0.5698)$, CIN II $(P=0.0746)$ or CIN III $(P=0.7366)$ compared to women with normal cytomorphological results. 


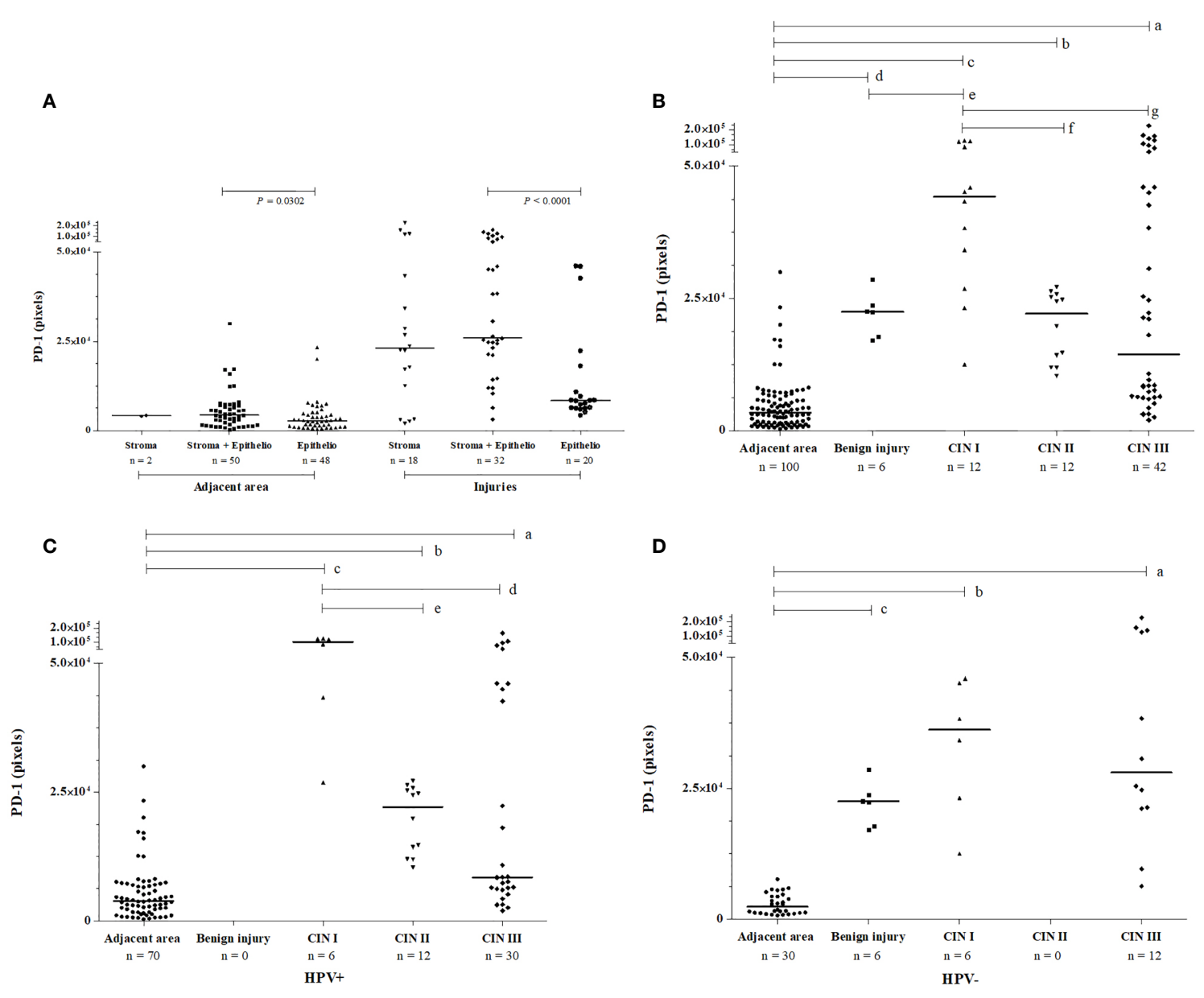

FIGURE 1 | Pattern of PD-1 immunochemistry labeling observed in cervical samples, according to (A) the tissue location in injured and uninjured adjacent areas, (B) the severity of lesion irrespective to HPV infection, (C) in the presence of HPV infection, and (D) the absence of HPV infection. PD-1 labeling was analyzed by two independent pathologists, and the intensity of the labeling (pixels) was quantified in three fields per slide. Data were presented as medians, and the comparisons were performed using the Kruskal-Wallis test followed by Mann Whitney $U$ test. In graph B, PD-1 levels were high irrespective of the severity of cervical lesions, CIN III (in a, $P<0.0001$ ); CIN II (in b, $P<0.0001$ ); CIN I (in c, $P<0.0001$ ); and benign lesions (in d, $P<0.0001$ ) compared to the uninjured adjacent area; and between benign lesion vs. CIN I (in e, $P=0.0131$ ); however, CIN I lesions showed the highest PD-1 level compared to the CIN II (in $\mathrm{f}, P=0.0014$ ) and $\mathrm{CIN}$ III (in $\mathrm{g}, P=0.0172$ ). In graph $\mathrm{C}$, in presence of HPV the PD-1 levels were high in CIN III (in a, $P<0.0001$ ), CIN II (in b, $P<0.0001$ ), and CIN I (in C, $P<0.0001$ ) compared to uninjured tissue, and lower PD-1 levels were observed in CIN III (in d, $P=0.0048$ ) and CIN II (in e, $P=0.0012$ ) compared to the levels in low-grade lesion CIN I. In graph D, in women non-infected by HPV, high PD-1 levels were also observed in CIN III (in a, $P<0.0001$ ), CIN I (in b, $P=0.0001$ ), and benign injury (in c $P=0.0001$ ) compared to the uninjured adjacent area.

\section{Association of the PDCD1 Gene Expression in the Cervical Lesion With
$P D C D 1$ Polymorphism}

The presence of cervical injury was not associated with a greater PDCD1 expression by exfoliative cervical cells when compared to cervical samples from women with a normal cytomorphological smear (Figure 3A). However, considering samples altogether, the mutant $-606 \mathrm{~A}$ allele in single or double dose was associated with higher $P D C D 1$ gene expression in cervical cells compared to the wild type -606GG genotype (Figure 3B). There was no statistical difference $(P=0.4692)$ between $P D C D 1$ expression levels in lesions of different severities in carriers of the $-606 \mathrm{GG}$ genotype (Figure 3C). However, among carriers of the $-606 \mathrm{~A}$ allele in homo or heterozygosis, the expression of PDCD1 was higher in exfoliative cells of patients exhibiting high-grade CIN III lesions compared to those presenting benign $(P=0.0453)$ or CIN II $(P=0.0233)$ lesions (Figure 3D). Moreover, despite no association of HPV-infection with PDCD1 expression $(\mathrm{P}=0.8329)$ was observed (Figure 3E), the presence of HPV increased PDCD1 expression, particularly in women presenting CIN I lesion (Figures 3F, G), a finding that may have been influenced by the $-606 \mathrm{~A}$ allele (Figure $3 \mathbf{H}$ ).

\section{Association Between PD-1 Protein Levels and PDCD1 Polymorphism}

We also evaluated whether the PD-1 tissue levels were associated with the presence of the rare PDCD1 $-606 \mathrm{G}>\mathrm{A}$ polymorphic sites. Considering the dominant model for the rare allele, women 


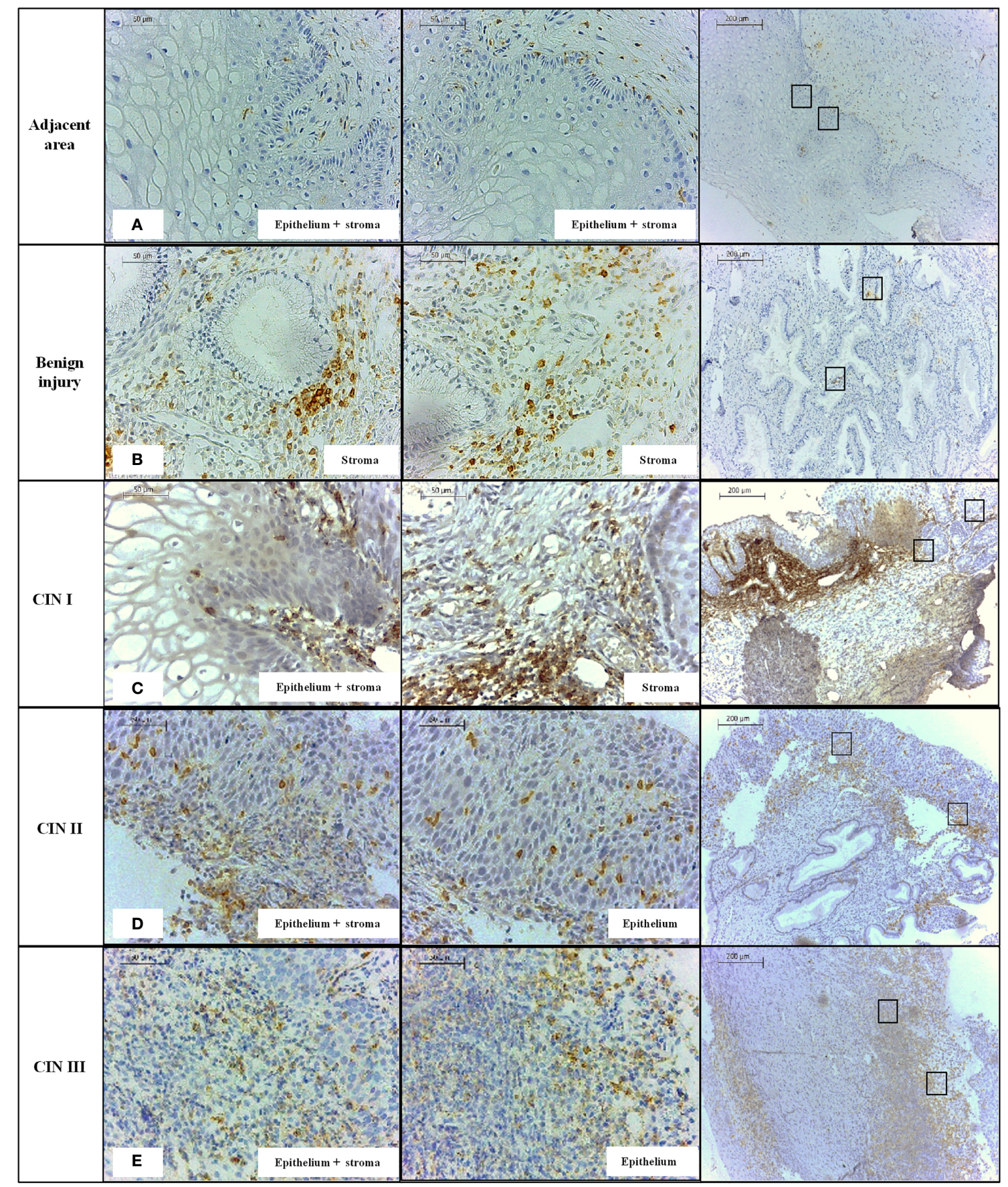

FIGURE 2 | Immunohistochemistry labeling of PD-1 level observed in specimens obtained from the mucosa of the uterine cervix, stratified according to the presence or not of the lesion, and according to the severity of the cervical lesion. (A) cervix without lesion, (B) benign injury, (C) CIN I, (D) CIN II, (E) CIN III, at 100X and 400X magnifications. PD-1 protein was primarily detected in the stratified epithelium and stroma of the cervical mucosa.

carrying the A allele in homozygosis or heterozygosis $(\mathrm{n}=46$, median $=7,381$ pixels) exhibited increased PD-1 levels in cervical samples when compared to those homozygous for the $G$ allele ( $\mathrm{n}=126$, median $=5,697$ pixels, $P=0.0234)$ (Figure 4A). Besides, the association of PDCD1 -606A allele with the PD-1 expression was strengthened when we specifically evaluated women with high-grade cervical lesions (CIN III); i.e., women carrying the -606A allele at homo- or heterozygosis exhibited higher PD-1 levels in the cervical lesions when compared to women carrying the homozygous $-606 \mathrm{G}$ allele (GA + AA with 
TABLE 2 | Allelic and genotypic frequency of the promoter region PDCD1-606 G>A (rs36084323) polymorphism observed in women exhibiting grades of cervical lesions, stratified according to i) presence or not of the HPV infection, ii) cytological/histological alterations, and iii) cellular ploidy.

\begin{tabular}{|c|c|c|c|c|c|c|c|c|c|c|c|c|}
\hline \multirow[t]{3}{*}{ Patients characteristics } & \multicolumn{12}{|c|}{ PDCD1 (rs36084323) } \\
\hline & \multicolumn{2}{|c|}{ GG } & \multicolumn{2}{|c|}{ GA+AA } & \multirow[t]{2}{*}{$P$} & \multirow[t]{2}{*}{ OR (Cl-95\%) } & \multicolumn{2}{|c|}{ G } & \multicolumn{2}{|c|}{ A } & \multirow[t]{2}{*}{$\boldsymbol{P}$} & \multirow[t]{2}{*}{ OR (Cl-95\%) } \\
\hline & $N=231$ & $83.7 \%$ & $\mathrm{~N}=45$ & $16.3 \%$ & & & $N=504$ & $91.3 \%$ & $\mathrm{~N}=48$ & $8.7 \%$ & & \\
\hline \multicolumn{13}{|l|}{ HPV Infection } \\
\hline Yes & 83 & 35.9 & 17 & 37.8 & 0.8659 & $0.92(0.48-1.79)$ & 182 & 36.1 & 18 & 37.5 & 0.8757 & $0.94(0.51-1.74)$ \\
\hline No & 148 & 64.1 & 28 & 62.2 & & & 322 & 63.9 & 30 & 62.5 & & \\
\hline Total & 231 & 100.0 & 45 & 100.0 & & & 504 & 100.0 & 48 & 100.0 & & \\
\hline \multicolumn{13}{|l|}{ Cytological alterations } \\
\hline HGSIL & 55 & 27.8 & 16 & 40.0 & 0.3018 & $\mathrm{n} / \mathrm{a}$ & 125 & 28.8 & 17 & 40.5 & 0.2864 & $\mathrm{n} / \mathrm{a}$ \\
\hline ASC-US, ASC-H and LGSIL & 62 & 31.3 & 10 & 25.0 & & & 133 & 30.6 & 11 & 26.2 & & \\
\hline No atypias & 81 & 40.9 & 14 & 35.0 & & & 176 & 40.6 & 14 & 33.3 & & \\
\hline Total & 198 & 100.0 & 40 & 100.0 & & & 434 & 100.0 & 42 & 100.0 & & \\
\hline \multicolumn{13}{|c|}{ Presence of histological alterations } \\
\hline Presence of $\mathrm{CIN}$ & 118 & 56.5 & 23 & 56.1 & 1.0000 & $1.01(0.52-1.99)$ & 259 & 56.8 & 23 & 52.3 & 0.6337 & $1.20(0.64-2.23)$ \\
\hline Absence of $\mathrm{CIN}$ & 91 & 43.5 & 18 & 43.9 & & & 197 & 43.2 & 21 & 47.7 & & \\
\hline Total & 209 & 100.0 & 41 & 100.0 & & & 456 & 100.0 & 44 & 100.0 & & \\
\hline \multicolumn{13}{|l|}{ Histological alterations } \\
\hline CIN III & 48 & 23.0 & 10 & 24.4 & 0.8669 & $\mathrm{n} / \mathrm{a}$ & 106 & 23.2 & 10 & 22.7 & 0.7133 & $\mathrm{n} / \mathrm{a}$ \\
\hline CIN ॥ & 51 & 24.4 & 11 & 26.8 & & & 113 & 24.8 & 11 & 25.0 & & \\
\hline $\mathrm{CINI}$ & 19 & 9.1 & 2 & 4.9 & & & 40 & 8.8 & 2 & 4.5 & & \\
\hline Benign injury & 33 & 15.8 & 8 & 19.5 & & & 72 & 15.8 & 10 & 22.7 & & \\
\hline Uninjured & 58 & 27.8 & 10 & 24.4 & & & 125 & 27.4 & 11 & 25.0 & & \\
\hline Total & 209 & 100.0 & 41 & 100.0 & & & 456 & 100.0 & 44 & 100.0 & & \\
\hline \multicolumn{13}{|l|}{ Cellular ploidy } \\
\hline Aneuploidy & 22 & 24.2 & 3 & 12.0 & 0.2737 & $2.34(0.64-8.57)$ & 47 & 22.8 & 3 & 11.5 & 0.3092 & $2.27(0.65-7.88)$ \\
\hline Diploidy & 69 & 75.8 & 22 & 88.0 & & & 159 & 77.2 & 23 & 88.5 & & \\
\hline Total & 91 & 100.0 & 25 & 100.0 & & & 206 & 100.0 & 26 & 100.0 & & \\
\hline
\end{tabular}

Atypical squamous cells of undetermined significance (ASC-US), atypical squamous cells-not excluding high-grade squamous intraepithelial lesion (ASC-H), the low-grade squamous intraepithelial lesion (LGSIL), the high-grade squamous intraepithelial lesion (HGSIL), cervical intraepithelial neoplasia (CIN). N, sample number; P, P-value; G, wild allele; A, variant allele; OR, odds ratio and $95 \% \mathrm{Cl}$, confidence interval. The frequencies of alleles and genotypes were compared using the two-tailed Fisher's exact and Chi-square tests.

the median of 48,117 pixels $v s$. GG with the median of 8,539 pixels, $P=0.0010$ ) (Figure 4B). However, PD-1 levels in uninjured adjacent tissue were not associated with the $-606 \mathrm{G}>\mathrm{A}$ variation site $(\mathrm{GA}+\mathrm{AA}$ with the median of 3,358 pixels $v s$. $G G$ with the median of 3,409 pixels, $P=0.8646$ ) (Figure 4C). In the presence of HPV infection, the high PD-1 levels previously associated with the presence of the $-606 \mathrm{~A}$ allele was not observed anymore (Figures 4D, E); however, the influence of HPV infection on PD-1 levels continue to be observed for high-grade CIN III lesions even being in less magnitude (Figure 4F).

\section{Predicted miRNA and PDCD1 rs36084323 SNP Association}

Considering the discrepancy regarding the results of the protein (Figure 4F) and gene expression (Figure 3H) levels, we further evaluated the differential targeting of miRNAs at the PDCD1 -606 variation site. An in-silico study showed that the hsa-miR204-3p binds exclusively to the $G$ allele, whereas the hsa-miR6798-5p, hsa-miR-6775-5p, and hsa-miR-4776-5p bind only to the $\mathrm{A}$ allele, and the hsa-miR-6771-5p targeted both alleles. Notably, the miRNAs that targeted the $-606 \mathrm{G}>\mathrm{A}$ variation site were included among the 2,586 miRNAs that have been predicted to target the PDCD1 gene, according to the mirDIP analysis (Figure 5).
In summary, our results showed that the $-606 \mathrm{~A}$ allele is rare in our population and, considering the dominant model, women carrying the $-606 \mathrm{AX}$ genotype $(\mathrm{X}=\mathrm{A}$ or $\mathrm{G})$ are more likely to respond to $\mathrm{HPV}$-induced cervical lesions with decreased production of PD-1, and the intensity and pattern of labeling is related to the degree of the cervical injury.

\section{DISCUSSION}

Since healthy cervical specimens are not easily available due to ethical reasons, in this study we evaluated PD-1 expression in cervical biopsies obtained from patients presenting several stages of the cervical lesion (injured areas) and used, as controls, the adjacent uninjured cervical areas. Irrespective of the severity of the lesion, injured cervical specimens overexpressed PD-1 when compared to the adjacent uninjured area, and particularly observed in the stromal layer (Figure 1A). Notably, samples presenting high-grade (CIN II-III) lesions expressed less PD-1 when compared to low-grade (CIN I) lesions (Figure 1B). PD-1 expression predominated in the stroma in low-grade lesions, and the epithelium in high-grade lesions (Figure 2). The stroma-rich $\mathrm{T}$ cell-infiltrate in low-grade cervical lesions associated with the increased tissue PD-1 (Hemmat and Bannazadeh Baghi, 2019) 


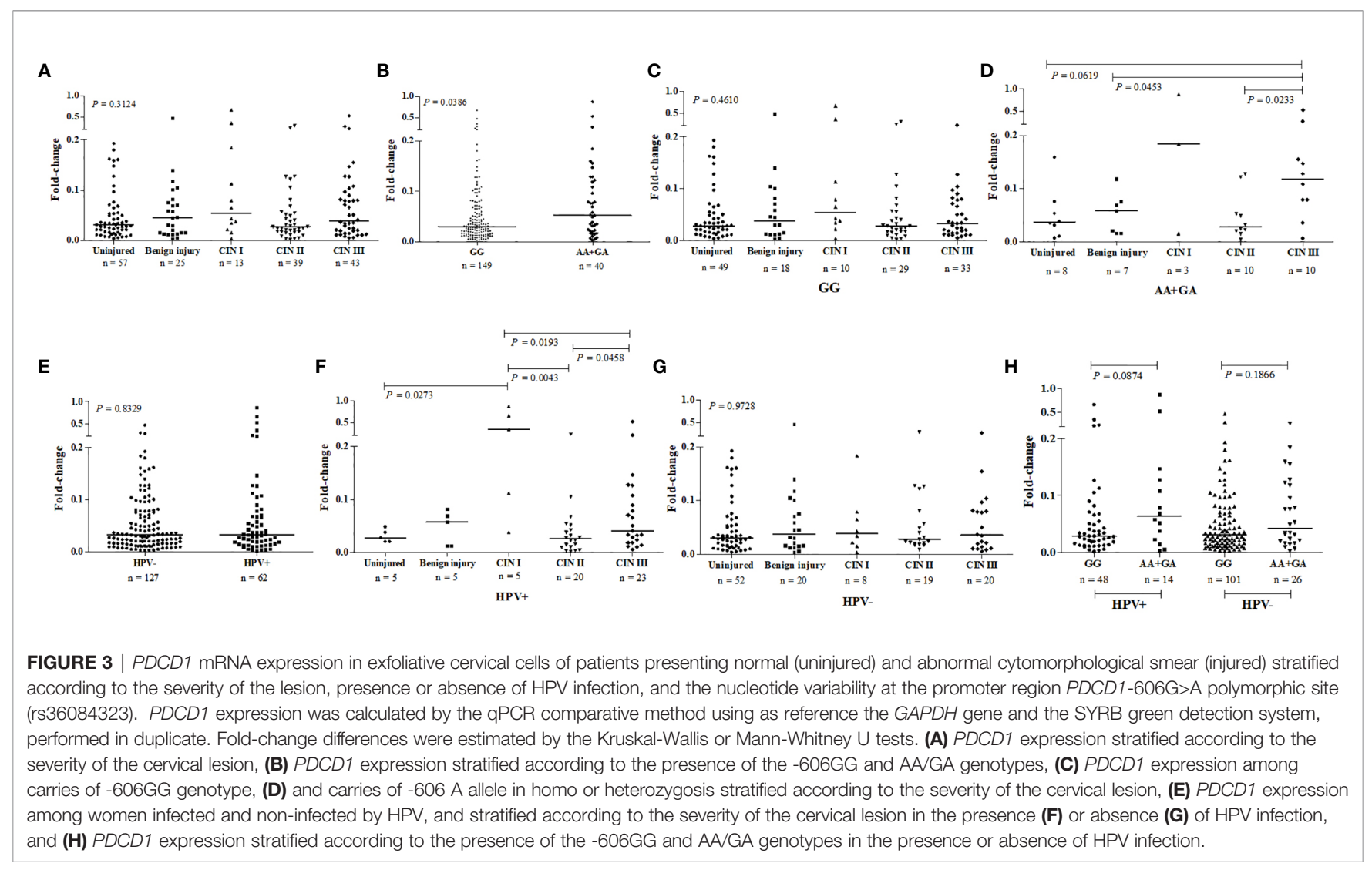

primarily reflect the severity of inflammation associated with HPV infection (Yang et al., 2013), whereas the expression at the epithelium strongly indicates the role of $\mathrm{PD}-1$ on the progression of the cervical lesions (Yang et al., 2017; Chang et al., 2018; Medeiros et al., 2018).

Considering that the magnitude of the PDCD1 gene expression has been associated with the PDCD1 -606 G>A polymorphic site (Ishizaki et al., 2010), we further investigated the relationship between alleles/genotypes with the magnitude of PD-1 cervical expression. First, we observed that the PDCD1 -606AA genotype was rare in our population (1.1\%), and according to the data reported at the 1000 Genomes Phase 3 database (The 1000 Genomes Project Consortium, 2015), the promoter region $P D C D 1-606 \mathrm{G}>\mathrm{A}$ (rs36084323) polymorphic site presents diverse allele frequency distribution in worldwide populations (1000 Genomes Project Phase 3 Allele Frequencies rs36084323 Snp; Auton et al., 2015), being frequent in Asians (1000 Genomes Project Phase 3 Allele Frequencies rs36084323 Snp), particularly in Chinese (21.9\%) and Japanese (25\%) populations (Hua et al., 2011; Sasaki et al., 2014; Hou et al., 2017). The presence of the $-606 \mathrm{~A}$ allele was not associated with the risk for the development of HPV infection, probably because of the low frequency of the mutant allele in our population. According to the frequency of the $-606 \mathrm{~A}$ in our population, a cohort of 1,834 individuals would be necessary to discriminate susceptibility/protection alleles.

Women carrying the $-606 \mathrm{~A}$ allele in homozygosis or heterozygosis showed a significant increase in the PDCD1 gene expression and PD-1 protein level when compared to those who carry the $-606 \mathrm{G}$ allele in homozygosis. In HPV-non-infected women, the PDCD1 expression was irrespective of the severity of the lesion, but in the presence of HPV infection, the PDCD1 expression was significantly increased in CIN I lesions, which may suggest a viral attempt to evade immune response against infection, favoring viral persistence (Yang et al., 2013). The PD-1 protein level in CIN I lesions was also high in HPV-infected women compared to non-infected women $(P=0.0649)$. In contrast, HPV decreased the PD-1 protein levels in CIN III $(P=0.0148)$, even though the protein levels remained significantly increased compared to the uninjured adjacent area, indicating that the HPV infection is associated with the cervical transformation (Martins et al., 2014). Noteworthy, the $-606 \mathrm{G}>\mathrm{A}$ variation site did not influence cervical $\mathrm{PD}-1$ protein levels in adjacent uninjured tissue indicating that, besides the genetic background, local microenvironment factors such as local inflammation may have a role

The functional implication of the PDCD1 -606G $>\mathrm{A}$ polymorphism on the magnitude of $\mathrm{PD}-1$ production has been attributed to the target site of the ubiquitin-converting enzyme 2 (UCE-2) transcription regulator (GGCCG in position -610 to -606). The $-606 \mathrm{G}$ allele was associated with higher relative expression of PDCD1 mRNA in peripheral blood mononuclear cells of Japanese and Filipino patients exhibiting subacute sclerosing panencephalitis due to measles infection (Ishizaki et al., 2010), and with lower survival in patients with non-small cell lung cancer (Sasaki et al., 2014). Additionally, the -606GG genotype was associated with protection against the development 

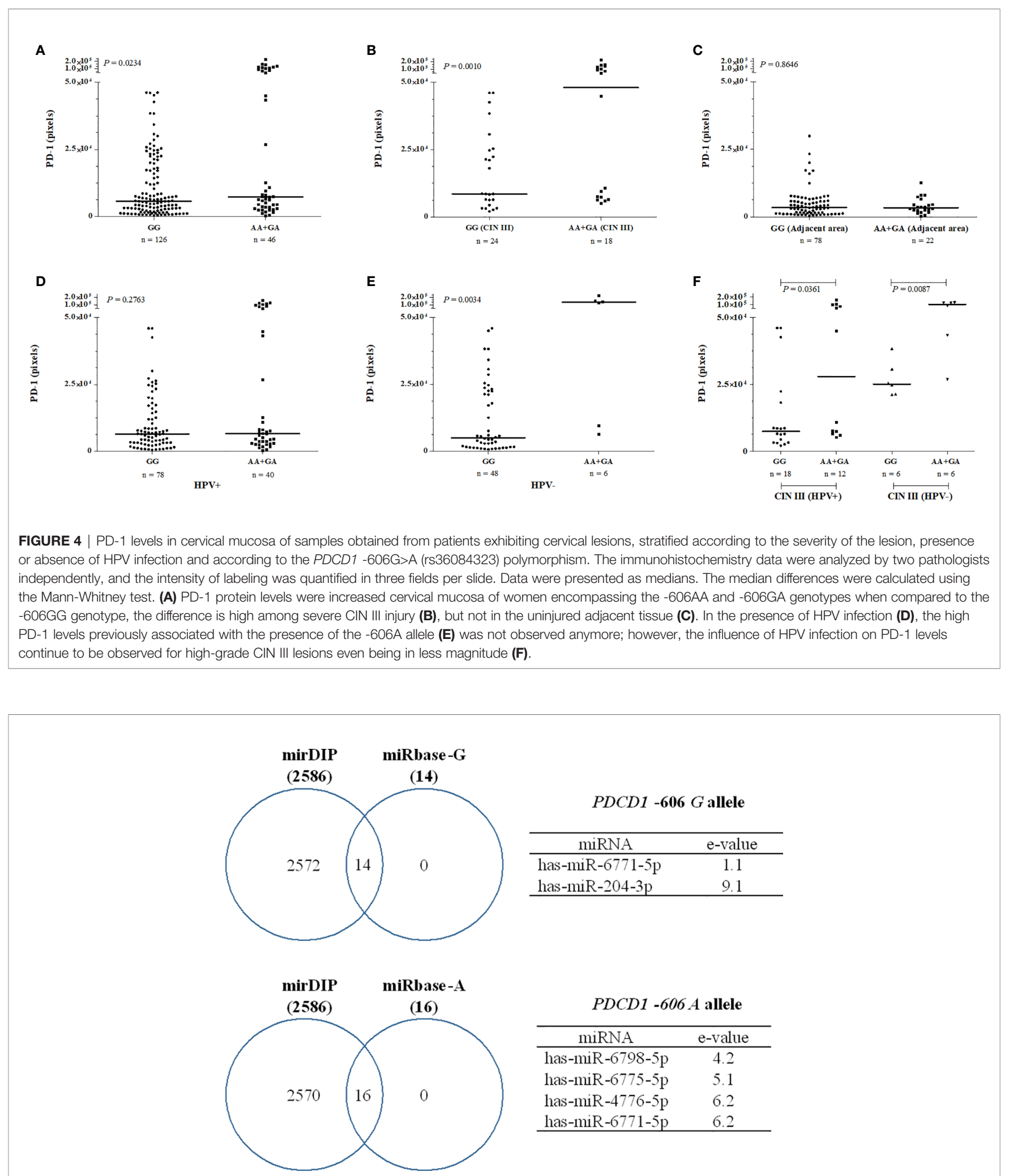

$P D C D 1-606 A$ allele

\begin{tabular}{cc}
\hline miRNA & e-value \\
\hline has-miR-6798-5p & 4.2 \\
has-miR-6775-5p & 5.1 \\
has-miR-4776-5p & 6.2 \\
has-miR-6771-5p & 6.2 \\
\hline
\end{tabular}

FIGURE 5 | Predicted miRNAs that target the PDCD1 -606G>A (rs36084323) polymorphic site. Binding affinity was evaluated using miRbase and mirDIP software and expressed as e-values, in which high affinity is represented by low e-values and vice-versa. 
and progression of breast cancer in women from Northeastern China; however, the A allele and the AA genotype were more frequent in patients exhibiting the p53 protein, a marker of biologically aggressive breast cancer (Hua et al., 2011). The PDCD1 -606AA genotype was also associated with chronic hepatitis $B$ virus (HBV) infection in the Chinese population, a viral infection that may progress to hepatocarcinoma (Hou et al., 2017). Altogether, these studies indicate a differential role of the PDCD1 -606G $>$ A polymorphic site according to the major subjacent cancer or viral disorder. In our study, we reported that the PDCD1 expression and PD-1 protein levels were associated with the $-606 \mathrm{~A}$ allele, and were modulated by HPV in severe tissue damage, suggesting that other mediators induced during the HPV infection progression may play an additional role.

Among the myriad of transcriptional and post-transcriptional elements that may differentially target gene polymorphic sites, the UCE-2 transcription regulator, which modulates the PDCD1-606 G>A polymorphic site (Ishizaki et al., 2010), has not been previously evaluated in the context of the progression of the HPV infection. On the other hand, several miRNAs have been associated with HPV lesion progression (Pardini et al., 2018; Pulati et al., 2019), and little is known regarding miRNA targeting the PDCD1-606 G>A region. Considering that virus infection may change the miRNA cell repertoire expression (Park et al., 2017; Chirayil et al., 2018; Del Mar Díaz-González et al., 2019), and that miRNA may also regulate gene expression at the transcriptional level (Lytle et al., 2007; Ørom et al., 2008; Place et al., 2008; Zhang et al., 2014), we conducted a bioinformatics analysis to predict miRNA interaction with the PDCD1-606G>A polymorphic site. Three miRNAs were predicted to bind to the mutant A allele: i) the hsa-MiR-6798-5p up-regulates decidual NK cells in recurrent spontaneous abortion (Sfera et al., 2015), ii) the hsa-MiR-6775 is reported to silence the transcription of the alpha 7-cholinergic nicotinic receptor gene (CHRNA7) expressed on lymphocyte surface and associated with lymphocyte anergy, $\mathrm{T}$ regulatory cell differentiation and immunologic tolerance, which consequently may predispose to cancer development ( $\mathrm{Li}$ et al., 2018), and iii) the hsa-MiR-4776-5p specifically targets the nuclear factor Kappa B inhibitor beta (NFKBIB) mRNA in Influenza A virus-infected cells, leading to activation of NF$\mathrm{kB}$, and survival of infected cells (Othumpangat et al., 2017). The hsa-MiR-6771-5p binds to the $-606 \mathrm{G}$ alleles with high affinity (e-value $=1.1)$ and weakly to the mutant $A$ allele (e-value $=6.2$ ), and it is involved in ZIKA-associated microcephaly. This miRNA shares the same sequence of the ZIKV genome and human genes associated with microcephaly (McLean et al., 2017). Finally, the hsa-MiR-204-3p targets the wild PDCD1 $-606 \mathrm{G}$ allele, and several studies report that this miRNA is a protective factor against cancer development by different cellular mechanisms depending upon the cell origin (Cui et al., 2014; Koga et al., 2018; Li et al., 2019; Xi et al., 2020). Besides targeting the PDCD1 gene, these miRNAs may also be associated with cell transformation induced by viruses and may share sequences associated with virus infection complications. Therefore, a balance between transcriptional and posttranscription factors together with genetic variability may account for the final result that may halt or permit virus spread and cell transformation.

Concluding, this study showed that PD-1 protein levels are increased in $\mathrm{HPV}$-induced cervical lesions, irrespective of the severity of the injury. In CIN I lesions, the highest PD-1 levels were observed in the inflammatory infiltrating cells of the stroma, whereas in high-grade CIN III lesions, the high PD-1 expression was observed in epithelial cells. In CIN I, the high levels of PD-1 were associated with increased PDCD1 expression in HPVinfected samples, whereas in CIN III the presence of HPV induced a decrease in PDCD1 expression and of PD-1 levels in carriers of the $-606 \mathrm{~A}$ allele, suggesting the possible gene regulation by miRNAs. Indeed, we identified some miRNAs specifically targeting the $-606 \mathrm{~A}$ allele region, which may be modulated by the presence of HPV, and may be involved in the progression of the cervical lesion. Future studies are needed to validate the role of these miRNAs in cervical cancer pathogenesis.

\section{DATA AVAILABILITY STATEMENT}

The original contributions presented in the study are publicly available in NCBI using accession number PRJNA734653.

\section{ETHICS STATEMENT}

The studies involving human participants were reviewed and approved by Ethics Committee of the Aggeu Magalhães Institute (CAAE: 51111115.9.0000.5190). The patients/participants provided their written informed consent to participate in this study.

\section{AUTHOR CONTRIBUTIONS}

MS, FM, NL-S, and ED conceived, designed the study, did the formal analysis, and wrote the paper. MS, NS, FG, TG, CP, and MCS conducted the experimental work. LP, MR, MM, and SW followed-up patients and performed cytopathological and coloscopy evaluations. NL-S and ED applied for financial support and managed the project. All authors contributed to the article and approved the submitted version.

\section{FUNDING}

This work was supported by grants from i) Brazilian Health Ministry Project DECIT-FINEP, (Grants \#1299-13; 401700/ 2015-1); ii) CAPES (PROCAD grant \#88881-068436/2014-09 and Finance code 001); iii) Foundation for Science and Technology of the State of Pernambuco (FACEPE) (Grant \#PROEP-APQ16804.01/15 and fellowship \#IBPG-0849-4.01/16 
to FM); iv) Brazilian National Council for Scientific and Technological Development (CNPq) (grants \#310364/2015-9 and \#310892/2019-8 to NL-S and \#302060/2019.7 to ED). The funders had no role in study design, data collection, and analysis, decision to publish, or preparation of the manuscript.

\section{REFERENCES}

Ørom, U. A., Nielsen, F. C., and Lund, A. H. (2008). MicroRNA-10a Binds the 5'UTR of Ribosomal Protein mRNAs and Enhances Their Translation. Mol. Cell 30 (4), 460-471. doi: 10.1016/j.molcel.2008.05.001

Aggarwal, B. B., Shishodia, S., Sandur, S. K., Pandey, M. K., and Sethi, G. (2006). Inflammation and Cancer: How Hot is the Link? Biochem. Pharmacol. 72, 1605-1621. doi: 10.1016/j.bcp.2006.06.029

(2020) 1000 Genomes Project Phase 3 Allele Frequencies rs36084323 Snp. Available at: http://www.ensembl.org/Homo_sapiens/Variation/Population? $\mathrm{db}=$ core; $\mathrm{v}=$ rs36084323; vdb=variation (Accessed in April 15, 2020).

Auton, A., Abecasis, G. R., Altshuler, D. M., Durbin, R. M., Bentley, D. R., Chakravarti, A., et al. (2015). A Global Reference for Human Genetic Variation. Nature 526, 68-74. doi: 10.1038/nature15393

Boussiotis, V. A. (2016). Molecular and Biochemical Aspects of the PD-1 Checkpoint Pathway. N Engl. J. Med. 375, 1767-1778. doi: 10.1056/ NEJMra1514296

Chang, H., Hong, J. H., Lee, J. K., Cho, H. W., Ouh, Y. T., Min, K. J., et al. (2018). Programmed Death-1 (PD-1) Expression in Cervical Intraepithelial Neoplasia and its Relationship With Recurrence After Conization. J. Gynecol. Oncol. 29, 1-14. doi: 10.3802/jgo.2018.29.e27

Chirayil, R., Kincaid, R. P., Dahlke, C., Kuny, C. V., Dalken, N., Spohn, M., et al. (2018). Identification of Virus-Encoded microRNAs in Divergent Papillomaviruses. PloS Pathog. 14 (7), e1007156. doi: 10.1371/ journal.ppat.1007156

Cui, Z. H., Shen, S. Q., Chen, Z. B., and Hu, C. (2014). Growth Inhibition of Hepatocellular Carcinoma Tumor Endothelial Cells by miR-204-3p and Underlying Mechanism. World J. Gastroenterol. 20 (18), 5493-5504. doi: 10.3748/wjg.v20.i18.5493

Del Mar Díaz-González, S., Rodríguez-Aguilar, E. D., Meneses-Acosta, A., Valadez-Graham, V., Deas, J., Gómez-Cerón, C., et al. (2019). Transregulation of microRNA miR-21 Promoter by AP-1 Transcription Factor in Cervical Cancer Cells. Cancer Cell Int. 19, 214. doi: 10.1186/ s12935-019-0931-x

De Oliveira, C. M., Fregnani, J. H. T. G., and Villa, L. L. (2019). Hpv Vaccine: Updates and Highlights. Acta Cytol. 63, 159-168. doi: 10.1159/000497617

Grivennikov, S. I., Greten, F. R., and Karin, M. (2010). Immunity, Inflammation, and Cancer. Cell 140, 883-899. doi: 10.1016/j.cell.2010.01.025

Hemmat, N., and Bannazadeh Baghi, H. (2019). Association of Human Papillomavirus Infection and Inflammation in Cervical Cancer. Pathog. Dis. 77, ftz048. doi: 10.1093/femspd/ftz048

Hollander, P., Amini, R. M., Ginman, B., Molin, D., Enblad, G., and Glimelius, I. (2018). Expression of PD-1 and PD-L1 Increase in Consecutive Biopsies in Patients With Classical Hodgkin Lymphoma. PloS One 13, 1-16. doi: 10.1371/ journal.pone.0204870

Hou, Z., Zhou, Q., Lu, M., Tan, D., and Xu, X. (2017). A Programmed Cell Death-1 Haplotype is Associated With Clearance of Hepatitis B Virus. Ann. Clin. Lab. Sci. 47, 334-343.

Hua, Z., Li, D., Xiang, G., Xu, F., Jie, G., Fu, Z., et al. (2011). PD-1 Polymorphisms are Associated With Sporadic Breast Cancer in Chinese Han Population of Northeast China. Breast Cancer Res. Treat 129, 195-201. doi: 10.1007/s10549011-1440-3

Ishida, Y., Agata, Y., Shibahara, K., and Honjo, T. (1992). Induced Expression of PD-1, a Novel Member of the Immunoglobulin Gene Superfamily, Upon Programmed Cell Death. EMBO J. 11, 3887-3895. doi: 10.1002/j.14602075.1992.tb05481.x

Ishizaki, Y., Yukaya, N., Kusuhara, K., Kira, R., Torisu, H., Ihara, K., et al. (2010). PD1 as a Common Candidate Susceptibility Gene of Subacute Sclerosing Panencephalitis. Hum. Genet. 127, 411-419. doi: 10.1007/s00439-009-0781-z

\section{ACKNOWLEDGMENTS}

We thank Viviane Carvalho for invaluable technical assistance and the Program for Technological Development in Tools for Health (PDTIS-FIOCRUZ).

Jiang, C., Cao, S. R., Li, N., Jiang, L., and Sun, T. (2019). PD-1 and PD-L1 Correlated Gene Expression Profiles and Their Association With Clinical Outcomes of Breast Cancer. Cancer Cell Int. 19, 1-9. doi: 10.1186/s12935019-0955-2

Kawahara, T., Ishiguro, Y., Ohtake, S., Kato, I., Ito, Y., Ito, H., et al. (2018). PD-1 and PD-L1 are More Highly Expressed in High-Grade Bladder Cancer Than in Low-Grade Cases: PD-L1 Might Function as a Mediator of Stage Progression in Bladder Cancer 11 Medical and Health Sciences 1112 Oncology and Carcinogenesis. BMC Urol. 18, 1-6. doi: 10.1186/s12894-018-0414-8

Keir, M. E., Butte, M. J., Freeman, G. J., and Sharpe, A. H. (2008). PD-1 and Its Ligands in Tolerance and Immunity. Annu. Rev. Immunol. 26, 677-704. doi: 10.1146/annurev.immunol.26.021607.090331

Koga, T., Migita, K., Sato, T., Sato, S., Umeda, M., Nonaka, F., et al. (2018). MicroRNA-204-3p Inhibits Lipopolysaccharide-Induced Cytokines in Familial Mediterranean Fever Via the Phosphoinositide 3-Kinase $\gamma$ Pathway. Rheumatol. (Oxford). 57 (4), 718-726. doi: 10.1093/rheumatology/kex451

Kozomara, A., Birgaoanu, M., and Griffiths-Jones, S. (2019). Mirbase: From microRNA Sequences to Function. Nucleic Acids Res. 47, D155-D162. doi: 10.1093/nar/gky1141

Lewinsky, H., Barak, A. F., Huber, V., Kramer, M. P., Radomir, L., Sever, L., et al. (2018). CD84 Regulates PD-1/PD-L1 Expression and Function in Chronic Lymphocytic Leukemia. J. Clin. Invest. 128, 5479-5488. doi: 10.1172/JCI96610

Li, D., Li, J., Jia, B., Wang, Y., Zhang, J., and Liu, G. (2018). Genome-Wide Identification of microRNAs in Decidual Natural Killer Cells From Patients With Unexplained Recurrent Spontaneous Abortion. Am. J. Reprod. Immunol. 80, e13052. doi: 10.1111/aji.13052

Li, X., Zhong, W., Xu, Y., Yu, B., and Liu, H. (2019). Silencing of Lncrna LINC00514 Inhibits the Malignant Behaviors of Papillary Thyroid Cancer Through miR-204-3p/CDC23 Axis. Biochem. Biophys. Res. Commun. 508 (4), 1145-1148. doi: 10.1016/j.bbrc.2018.12.051

Lytle, J. R., Yario, T. A., and Steitz, J. A. (2007). Target mRNAs are Repressed as Efficiently by microRNA-binding Sites in the 5' UTR as in the 3' Utr. Proc. Natl. Acad. Sci. U. S. A. 104 (23), 9667-9672. doi: 10.1073/pnas.0703820104

Manos, M., Ting, Y., Wright, D., Lewis, A., Broker, T., and Wolinsky, S. (1989). Use of Polymerase Chain Reaction Amplification for the Detection of Genital Human Papillomaviruses. Cancer Cells: Mol. Diag. of Human Cancer 7, 209214.

Marinelli, O., Annibali, D., Aguzzi, C., Tuyaerts, S., Amant, F., Morelli, M. B., et al. (2019). The Controversial Role of PD-1 and Its Ligands in Gynecological Malignancies. Front. Oncol. 9:1073. doi: 10.3389/fonc.2019.01073

Martins, A. E. S., Lucena-Silva, N., Garcia, R. G., Welkovic, S., Barbosa, A., Menezes, M. L. B., et al. (2014). Prognostic Evaluation of DNA Index in HIVHPV Co-Infected Women Cervical Samples Attending in Reference Centers for HIV-AIDS in Recife. PloS One 9, 1-8. doi: 10.1371/journal.pone.0104801

McLean, E., Bhattarai, R., Hughes, B. W., Mahalingam, K., and Bagasra, O. (2017). Computational Identification of Mutually Homologous Zika Virus miRNAs That Target Microcephaly Genes. Libyan. J. Med. 12:1. doi: 10.1080/ 19932820.2017.1304505

Medeiros, F. S., Martins, A. E. S., Gomes, R. G., De Oliveira, S. A. V., Welkovic, S., Maruza, M., et al. (2018). Variation Sites At the HLA-G 3' Untranslated Region Confer Differential Susceptibility to HIV/HPV Co-Infection and Aneuploidy in Cervical Cell. PloS One 13, 1-14. doi: 10.1371/journal.pone.0204679

Muenst, S., Läubli, H., Soysal, S. D., Zippelius, A., Tzankov, A., and Hoeller, S. (2016). The Immune System and Cancer Evasion Strategies: Therapeutic Concepts. J. Intern. Med. 279, 541-562. doi: 10.1111/joim.12470

Othumpangat, S., Bryan, N. B., Beezhold, D. H., and Noti, J. D. (2017). Upregulation of miRNA-4776 in Influenza Virus Infected Bronchial Epithelial Cells Is Associated With Downregulation of NFKBIB and Increased Viral Survival. Viruses 9:94. doi: 10.3390/v9050094 
Pardini, B., De Maria, D., Francavilla, A., Di Gaetano, C., Ronco, G., and Naccarati, A. (2018). MicroRNAs as Markers of Progression in Cervical Cancer: A Systematic Review. BMC Cancer. 18 (1), 696. doi: 10.1186/s12885-018-4590-4

Park, S., Eom, K., Kim, J., Bang, H., Wang, H., Ahn, S., et al. (2017). MiR-9, miR21, and miR-155 as Potential Biomarkers for HPV Positive and Negative Cervical Cancer. BMC Cancer 17 (1), 658. doi: 10.1186/s12885-017-3642-5

Place, R. F., Li, L. C., Pookot, D., Noonan, E. J., and Dahiya, R. (2008). MicroRNA373 Induces Expression of Genes With Complementary Promoter Sequences. Proc. Natl. Acad. Sci. U. S. A. 105 (5), 1608-1613. doi: 10.1073/pnas.0707594105

Pulati, N., Zhang, Z., Gulimilamu, A., Qi, X., and Yang, J. (2019). Hpv16(+) -miRNAs in Cervical Cancer and the Anti-Tumor Role Played by Mir-5701. J. Gene Med. 21 (11), e3126. doi: 10.1002/jgm.3126

Salmaninejad, A., Khoramshahi, V., Azani, A., Soltaninejad, E., Aslani, S., Zamani, M. R., et al. (2018). PD-1 and Cancer: Molecular Mechanisms and Polymorphisms. Immunogenetics 70, 73-86. doi: 10.1007/s00251-017-1015-5

Sasaki, H., Tatemaysu, T., Okuda, K., Moriyama, S., Yano, M., and Fujii, Y. (2014). PD-1 Gene Promoter Polymorphisms Correlate With a Poor Prognosis in nonSmall Cell Lung Cancer. Mol. Clin. Oncol. 2, 1035-1042. doi: 10.3892/ mco. 2014.358

Senba, M., and Mori, N. (2012). Mechanisms of Virus Immune Evasion Lead to Development From Chronic Inflammation to Cancer Formation Associated With Human Papillomavirus Infection. Oncol. Rev. 6, 135-144. doi: 10.4081/ oncol.2012.e17

Sfera, A., Cummings, M., and Osorio, C. (2015). Non-Neuronal Acetylcholine: The Missing Link Between Sepsis, Cancer, and Delirium? Front. Med. 2:56. doi: $10.3389 /$ fmed.2015.00056

Shinohara, T., Tanowaki, M., Ishida, Y., Kawaichi, M., and Honjo, T. (1994). Structure and Chromosomal Localization of the Human Pd-1 Gene (Pdcd1). Genomics 23, 704-706. doi: 10.1006/geno.1994.1562

Tamura, K., Peterson, D., Peterson, N., Stecher, G., Nei, M., and Kumar, S. (2011). Mega5: Molecular Evolutionary Genetics Analysis Using Maximum Likelihood, Evolutionary Distance, and Maximum Parsimony Methods. Mol. Biol. Evol. 28, 2731-2739. doi: 10.1093/molbev/msr121

Tao, L. H., Zhou, X. R., Li, F. C., Chen, Q., Meng, F. Y., Mao, Y., et al. (2017). A Polymorphism in the Promoter Region of PD-L1 Serves as a Binding-Site for SP1 and is Associated With PD-L1 Overexpression and Increased Occurrence of Gastric Cancer. Cancer Immunol. Immunother. 66, 309-318. doi: 10.1007/ s00262-016-1936-0

The 1000 Genomes Project Consortium. (2015). A global reference for human genetic variation. Nature 526, 68-74. doi: 10.1038/nature15393
Tokar, T., Pastrello, C., Rossos, A. E. M., Abovsky, M., Hauschild, A. C., Tsay, M., et al. (2018). MirDIP 4.1 - Integrative Database of Human microRNA Target Predictions. Nucleic Acids Res. 46, D360-D370. doi: 10.1093/nar/gkx1144

Wang, Y., Wang, H., Yao, H., Li, C., Fang, J. Y., and Xu, J. (2018). Regulation of PD-L1: Emerging Routes for Targeting Tumor Immune Evasion. Front. Pharmacol. 9:536. doi: 10.3389/fphar.2018.00536

Wieser, V., Gaugg, I., Fleischer, M., Shivalingaiah, G., Sprung, S., Lax, S. F., et al. (2018). BRCA1/2 and TP53 Mutation Status Associates With PD-1 and PD-L1 Expression in Ovarian Cancer. OncoTargets 9, 17501-17511. doi: 10.18632/oncotarget.24770

World Health Organization (2017). Human papillomavirus Vaccines: WHO Position Paper, May 2017-Recommendations. Vaccine 43, 5753-5755. doi: 10.1016/j.vaccine.2017.05.069

Xi, X., Teng, M., Zhang, L., Xia, L., Chen, J., and Cui, Z. (2020). MicroRNA-204-3p Represses Colon Cancer Cells Proliferation, Migration, and Invasion by Targeting HMGA2. J. Cell Physiol. 235 (2), 1330-1338. doi: 10.1002/jcp.29050

Yang, W., Lu, Y. P., Yang, Y. Z., Kang, J. R., Jin, Y. D., and Wang, H. W. (2017). Expressions of Programmed Death (PD)-1 and PD-1 Ligand (PD-L1) in Cervical Intraepithelial Neoplasia and Cervical Squamous Cell Carcinomas are of Prognostic Value and Associated With Human Papillomavirus Status. J. Obstet. Gynaecol. Res. 43, 1602-1612. doi: 10.1111/jog.13411

Yang, W., Song, Y., Lu, Y. L., Sun, J. Z., and Wang, H. W. (2013). Increased Expression of Programmed Death (PD)-1 and its Ligand PD-L1 Correlates With Impaired Cell-Mediated Immunity in High-Risk Human Papillomavirus-Related Cervical Intraepithelial Neoplasia. Immunology 139, 513-522. doi: 10.1111/imm.12101

Zhang, Y., Fan, M., Zhang, X., Huang, F., Wu, K., Zhang, J., et al. (2014). Cellular microRNAs Up-Regulate Transcription Via Interaction With Promoter TATA-box Motifs. RNA 20 (12), 1878-1889. doi: 10.1261/rna.045633.114

Conflict of Interest: The authors declare that the research was conducted in the absence of any commercial or financial relationships that could be construed as a potential conflict of interest.

Copyright (C) 2021 Silva, Medeiros, Silva, Paiva, Gomes, Costa e Silva, Gomes, Peixoto, Rygaard, Menezes, Welkovic, Donadi and Lucena-Silva. This is an open-access article distributed under the terms of the Creative Commons Attribution License (CC BY). The use, distribution or reproduction in other forums is permitted, provided the original author(s) and the copyright owner(s) are credited and that the original publication in this journal is cited, in accordance with accepted academic practice. No use, distribution or reproduction is permitted which does not comply with these terms. 